\title{
Status of theileriosis among herbivores in Iran: A systematic review and meta-analysis
}

\author{
Masoud Soosaraei ${ }^{1}$, Mousa Motavalli Haghi², Fariborz Etemadifar ${ }^{2}$, Mahdi Fakhar ${ }^{3}$, Saeed Hosseini Teshnizi ${ }^{4}$, \\ Hajar Ziaei Hezarjaribi ${ }^{3}$ and Shabnam Asfaram ${ }^{1}$
}

1. Student Research Committee, Department of Parasitology, School of Medicine, Mazandaran University of Medical Sciences, Sari, Iran; 2. Student Research Committee, Department of Parasitology and Mycology, School of Medicine, Hamadan University of Medical Sciences, Hamadan, Iran; 3. Molecular and Cell Biology Research Center (MCBRC), Department of Parasitology, School of Medicine, Mazandaran University of Medical Sciences, Sari, Iran; 4. Biostatistician, Infectious and Tropical Diseases Research Center, Hormozgan University of Medical Sciences, Bandar Abbas, Iran.

Corresponding author: Mahdi Fakhar, e-mail: mahdif53@yahoo.com

Co-authors: MS: masoudsoosaraie@gmail.com, MMH: mossa2020@yahoo.com,FE: fariborzetemadi67@gmail.com, SHT: saeed.teshnizi@gmail.com,HZH: ziaei2000@yahoo.com, SA: shabnamdew90@yahoo.com

Received: 03-11-2017, Accepted: 20-02-2018, Published online: 19-03-2018

doi: 10.14202/vetworld.2018.332-341 How to cite this article: Soosaraei M, Haghi MM, Etemadifar F, Fakhar M, Teshnizi SH, Hezarjaribi HZ, Asfaram S (2018) Status of theileriosis among herbivores in Iran: A systematic review and meta-analysis, Veterinary World, 11(3): 332-341.

\begin{abstract}
Aim: Theileriosis is a protozoal disease caused by Theileria spp. mostly in warm-blooded vertebrates worldwide. It is one of the common tick-borne diseases among domestic animals in tropical and sub-tropical regions, which have a variety of unlikable effects on health economy and animal welfare. In the present study, the prevalence of theileriosis among domestic farm animals in Iran was systematically evaluated.

Methods: To identify the related papers, 10 English and Persian databases, including PubMed, Science Direct, Scopus, Web of Science, Medical Subject Headings, Google Scholar, Magiran, Barakatns (formerly Iranmedex), Elm net, and Scientific Information Database, were appraised for articles published throughout 1999-2017.

Results: A total of 56 papers, providing the examination of 11,317 cattle, 9394 sheep, 2991 buffaloes, 1504 horses, 600 goats, and 212 donkeys were analyzed, matching for the prevalence of theileriosis from different parts of Iran were permitted for our allowing checklist. The overall prevalence of theileriosis among domestic herbivores was expected to be $19 \%(95 \%$ confidence interval: $15 \%, 22 \%$ ). Our findings highlighted the average of the maximum prevalence in Razavi Khorasan (60.4\%) and West Azerbaijan (49.1\%) and the minimum in Mazandaran (1.1\%) and East Azerbaijan provinces (2.2\%), respectively. The high prevalence of Theileria infection in the herbivores (mainly sheep) verifies the well-known enzootic episode of theileriosis in Iran, predominantly in northeastern and western parts of the country.

Conclusion: Our results suggested updated and imperative information on the true burden of theileriosis in Iran. Moreover, it could be supporting the gaps among monitoring, prevention, and control arrangements to improve the health economy, particularly among dairy farm animals.
\end{abstract}

Keywords: epidemiology, Iran, livestock, systematic review, Theileria spp.

\section{Introduction}

Theileriosis is a tick-borne hemoprotozoal tropical disease in various warm-blooded vertebrates mainly domestic and wild mammals caused by protozoan parasites belonging to the Theileria spp. [1,2]. Theileria is a genus of protozoan that belongs to the phylum Apicomplexa (order: Piroplasmida and family: Theileriidae), which is transmitted by ixodid hard ticks acting as natural vectors. The parasite life cycle is well-known by extra-erythrocytic merogony in the lymphocytes and histiocytes, following by invasion of the red blood cells by the merozoites [3]. Although,

Copyright: Soosaraei, et al. Open Access. This article is distributed under the terms of the Creative Commons Attribution 4.0 International License (http://creativecommons.org/licenses/ by/4.0/), which permits unrestricted use, distribution, and reproduction in any medium, provided you give appropriate credit to the original author(s) and the source, provide a link to the Creative Commons license, and indicate if changes were made. The Creative Commons Public Domain Dedication waiver (http:// creativecommons.org/publicdomain/zero/1.0/) applies to the data made available in this article, unless otherwise stated.
Theileria parasite infect mainly a variety of both domestic and wild livestock, there is no proof that Theileria spp. are threats to human population $[2,4,5]$.

Cattle and buffaloes can be infected by various species of Theileria and infections differ from subclinical (known as mild) to malignant (known as severe). Almost nine mild and malignant species of Theileria causing bovine theileriosis are including Theileria mutans, Theileria buffeli, Theileria orientalis, Theileria velifera, Theileria taurotragi and Theileria parva (as malignant bovine theileriosis; known as East Coast fever), Theileria annulata (known as tropical bovine theileriosis), Theileria sergenti, and T. taurotragi, respectively. Likewise, at least seven spices including Theileria lestoquardi (formerly Theileria hirci), Theileria luwenshuni, Theileria uilenbergi (causing malignant ovine theileriosis), and Theileria separata, Theileria ovis, Theileria recondita (causing mild ovine theileriosis), and T. annulata are naturally causal agents of ovine theileriosis with worldwide 
distribution [6]; although recently, T. annulata, as causal agent of malignant bovine theileriosis, has been reported in southern Iran $[7,8]$.

Laboratory diagnosis of theileriosis was performed mostly by detecting schizonts in Giemsastained thick and thin smears from blood or lymph node fine needle aspiration. Several conventional and novel diagnostic tools vary from low to high sensitivity, such as polymerase chain reaction (PCR) test, enzyme-linked immunosorbent assays (ELISAs), or an indirect fluorescent antibody test (IFAT), were used for determining prevalence and differentiating the Theileria spp. [6,9-11]. In spite of the presence of a variety of studies concerning theileriosis among livestock in Iran, there is inapplicable data about the true burden of it in these animals to forecast the financial burden and well-known capacity for control and prevention planning.

Concerning the influences of theileriosis on economy and animal welfare, more deliberations would be crucial for the epidemiological aspects and the approaches to screening panels in Iran. To the best of our knowledge, there is no systematic review and meta-analysis on the subject of animal theileriosis in Iran; thus, the main goal of our study was to find out the present status of ovine, bovine, and equine theileriosis in the country.

\section{Methods}

\section{Ethical approval} study.

Ethical approval is not needed for this kind of

\section{Searching approach}

For searching purpose, 10 English and Persian databases, including PubMed, Science Direct, Scopus, Web of Science, Medical Subject Headings, Google Scholar, Magiran, Barakatkns (formerly Iranmedex), Elm net, and Scientific Information Database, were chosen during 1999-2017. To exploring the articles, the terms including: Theileria, Theileriosis, T. orientalis, T. annulata, T. hirci, T. lestoquardi, T. ovis, Theileria equi, cattle, buffalo, bovine, sheep, goat, ovine, caprine, horse, donkey, equine, and "Iran" alone or in combination were used. To avoid the risk of selection bias in this study, the inclusion criteria were clearly classified and studied. Experimental studies, clinical trials, duplicates, case reports, monkey, carnivores, camel, and studies out of Iran were expelled. All descriptive studies corresponding to the prevalence of ovine, bovine, and equine theileriosis were reviewed. The stages of the study plan are briefly explained in Figure-1.

\section{Data extraction}

The data were extracted from the included studies by four reviewers (M. Soosaraei, M. Motavalli Haghi, F. Etemadifar, and Sh.Asfaram), who used a standard form. Any disagreement was resolved by discussion between the four reviewers. If consensus could not be reached, two reviewers were consulted (M. Fakhar and H. Ziaei Hezarjaribi). The kappa index showed an agreement of $89 \%$ between the fives reviewers. The standard form consisted of the following variables: First author; year of publication, year of study, type of animal, place of conducted survey (Province), sample size, number of positive, and diagnostic laboratory methods (Table-1) [7,12-65]. The quality of selected studies was assessed using the STROBE scale (score under 7.75 low quality, 7.76-15.5 moderate and 15.623.5 moderate to height, and upper 23.6 height quality).

\section{Effect measures}

The outcome was the prevalence of Theileria, and this was obtained for each study by dividing the number of positive cases by the total sample size.

\section{Statistical analysis}

The prevalence of each study was collected, and according to the binomial distribution, standard error $\mathrm{SE}=\sqrt{\frac{\mathrm{p} \cdot \mathrm{q}}{\mathrm{n}}}$ for each study was calculated and the inverse of SE each study considered as the weight of that study. The effect size (ES) for each study and pooled outcome revealed as a forest plot (reported as ES with a $95 \%$ confidence interval $[95 \% \mathrm{CI}]$ ). Cochran's heterogeneity statistics based on Chisquare test Q-test ( $<0.1$ as heterogeneities) and the $\mathrm{I}^{2}$ statistic which describes the percentage of variation across studies (values of $25 \%, 50 \%$, and $75 \%$ indicate low, moderate, and high degrees of heterogeneity, respectively). At present heterogeneity, random effects model (Der Simonian Laird model) and otherwise applied fixed-effect model (Mantel Haenszel) were used to compute overall ES. Subgroup analyses were performed to investigate potential sources of heterogeneity from different sex and age. Egger's tests were used to evaluate publication bias. All statistical analyses were fulfilled with the statistical software package (Stata) version 11.1. (Stata Corp LP, College Station, TX, USA). $\mathrm{p}<0.05$ was measured statistically significant.

\section{Results}

Among each one of the databases investigated during 19 years from 1999 to 2017 , overall 56 articles were fitting to be integrated into our systematic review and meta-analysis. All papers were assigned and assessed the prevalence of theileriosis among herbivores including sheep, goat, cattle, buffalo, horse, and donkey in Iran. Absolutely, 11,317 cattle, 9394 sheep, 2991 buffaloes, 1504 horses, 600 goats, and 212 donkeys were analyzed, respectively. In general, because of the restricted data fulfilled on camel theileriosis in Iran, we included just articles correlated to the disease among domesticated herbivores except for camel.

The mean of scores for the STROBE scale was to be found 21.73 which performed quality of these studies was moderate to height. As indicated by a random effect meta-analysis $\left(I^{2}=98.94 \%, p<0.001\right)$ 


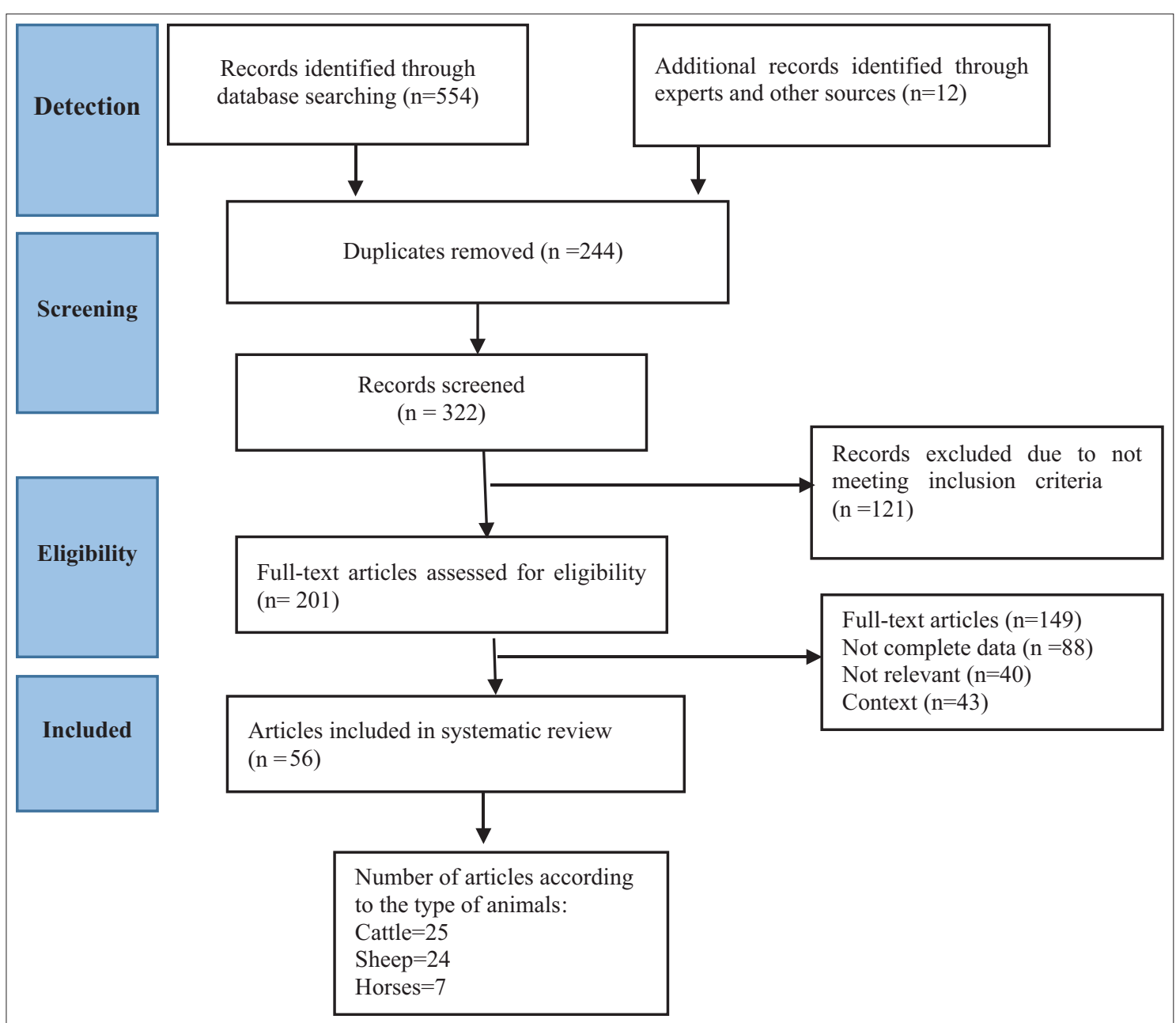

Figure-1: Flow diagram of classification of papers for inclusion in this systematic review and meta-analysis.

the pooled event of Theileria infection in Iran was acquired 19\% (95\% CI: 15\%, 22\%). The prevalence rate of ovine (sheep and goats), bovine (cattle and buffaloes), and equine (horses and donkeys); theileriosis was $23.0 \%(17.0-30.0 \%), 14.0 \%(11.0-19.0 \%)$, and $20.0 \%(11.0-30.0 \%)$, respectively; a significant statistically difference was observed among them $(\mathrm{z}=5.80$, $\mathrm{df}=2, \mathrm{p}=0.05$ ) (Figures-2 and 3).

Besides, our results showed the prevalence of Theileria infection among sheep (23\%) which was considerably too much than other herbivores $(\mathrm{p}<0.001)$; and prevalence of T. ovis and T. annulata in sheep and cattle was significantly higher than other ones, respectively $(\mathrm{p}<0.001)$.

In addition, the highest prevalence of $T$. equi infection in horses $19.0 \%$ (11.0-29.0\%) was detected by IFAT $(51 \%)$ and the lowest by microscopic methods $(7 \%)$. There was significant difference between prevalence of laboratory methods which used for diagnosing equine theileriosis for horses (Q-test $=137.25$, $\mathrm{df}=2, \mathrm{p}<0.001$ ).

The subgroup analysis showed PCR method had the most prevalence for sheep, 33.0\% (95\% CI: 20.0-48.0\%) and a significant difference between prevalence of Theileria infection and laboratory techniques used among sheep (Q-test $=9.5, \mathrm{df}=3$, $\mathrm{p}=0.02$ ). Moreover, our meta-analysis showed a significant difference among Theileria species in sheep (Q-test $=41.2, \mathrm{df}=3, \mathrm{p}<0.001)$ and cattle (Q-test $=180.43, \mathrm{df}=4, \mathrm{p}<0.001$ ), correspondingly. In addition, the analysis confirmed a significant difference between prevalence of Theileria infection and laboratory methods used for cattle (Q-test $=699.32$, $\mathrm{df}=5, \mathrm{p}<0.001)$.

The results of Egger's test for each of animal subgroups provided no evidence of publication bias in the studies $(\mathrm{p}>0.1)$ (Table-2). Therefore, it appears that both studies with low and high prevalence were contributed in this meta-analysis. The consequences of subgroup examination independently for type of laboratory methods and Theileria spp. infection showed that these two elements are two major sources of heterogeneity among prevalence of theileriosis for studies related to cattle and sheep, except horses.

\section{Discussion}

Our study is the first systematic review on theileriosis in Iran. Theileriosis is an economically important protozoal disease among domesticate livestock in Iran with overall 19\% infection rate, and the infection rates in sheep are $23 \%$, which cause terrible impacts 
Table-1: Baseline features of included studies.

\begin{tabular}{|c|c|c|c|c|c|c|}
\hline Animal & $\begin{array}{c}\text { No. of } \\
\text { examined }\end{array}$ & $\begin{array}{l}\text { No. of } \\
\text { positive }\end{array}$ & Species & $\begin{array}{l}\text { Laboratory } \\
\text { method }\end{array}$ & Place (province) & References \\
\hline Sheep & 1000 & 92 & T. lestoquardi & Microscopy & Fars & [12] \\
\hline Buffalo & 2700 & 82 & T. annulata & Microscopy & Khouzestan & [13] \\
\hline Cattle & 372 & 216 & T. annulata & Microscopy & Razavi Khorasan & [14] \\
\hline Sheep & 300 & 29 & T. lestoquardi & Microscopy & Lorestan & [15] \\
\hline Cattle & 390 & 15 & Theileria & Microscopy & $\begin{array}{l}\text { Chaharmahal va } \\
\text { Bakhtiari }\end{array}$ & [16] \\
\hline Sheep & 300 & 39 & Theileria & Microscopy & Mazandaran & [17] \\
\hline Cattle & 124 & 61 & Theileria & ELISA & West Azerbaijan & [18] \\
\hline Sheep & 200 & 7 & Theileria spp. & Microscopy & Mazandaran & [19] \\
\hline Sheep & 840 & 100 & Theileria spp. & Microscopy & South Khorasan & [20] \\
\hline Cattle & 600 & 34 & T. annulata & Microscopy & $\begin{array}{l}\text { Sistan and } \\
\text { Baluchestan }\end{array}$ & [21] \\
\hline Cattle & 252 & 26 & T. annulata & Microscopy & Sanandaj & {$[22]$} \\
\hline Cattle & NR & NR & T. annulata & $\begin{array}{l}\text { Semi-nested } \\
\text { PCR }\end{array}$ & $\begin{array}{l}\text { Tehran, Fars, } \\
\text { Sistan, and } \\
\text { Baluchestan }\end{array}$ & [23] \\
\hline Sheep & 150 & 71 & $\begin{array}{l}\text { Theileria spp., T. ovis, } \\
\text { T. lestoquardi }\end{array}$ & PCR & $\begin{array}{l}\text { Sistan and } \\
\text { Baluchestan }\end{array}$ & [24] \\
\hline Sheep & 100 & 60 & Theileria spp., T. lestoquardi & PCR & South Khorasan & {$[25]$} \\
\hline Cattle & 160 & 110 & Theileria spp., T. annulata & Microscopy & Razavi Khorasan & [26] \\
\hline Sheep & 100 & 56 & T. ovis, T. lestoquardi & PCR & $\begin{array}{l}\text { East and } \\
\text { South-East } \\
\text { provinces }\end{array}$ & [27] \\
\hline Sheep & 470 & 21 & T. lestoquardi, T. ovis & PCR & $\begin{array}{l}10 \text { various regions } \\
\text { of Iran }\end{array}$ & {$[28]$} \\
\hline Sheep & 220 & 181 & T. lestoquardi, T. ovis & $\begin{array}{l}\text { PCR and } \\
\text { microscopy }\end{array}$ & $\begin{array}{l}5 \text { various regions } \\
\text { in eastern half of } \\
\text { Iran }\end{array}$ & [24] \\
\hline Cattle & 160 & 16 & T. annulata and T. orientalis & $\begin{array}{l}\text { Semi-nested } \\
\text { PCR }\end{array}$ & Golestan & [29] \\
\hline Sheep & 200 & 11 & T. ovis & Microscopy & West Azerbaijan & {$[30]$} \\
\hline Cattle & 100 & 22 & T. annulata & IFAT & West Azerbaijan & \\
\hline Cattle & 160 & 20 & T. annulata & PCR & Golestan & {$[31]$} \\
\hline Cattle & & & T. annulata & PCR-RFLP & $\begin{array}{l}\text { Kurdistan and } \\
\text { West-Azerbaijan }\end{array}$ & [32] \\
\hline Cattle & 200 & 63 & T. annulata & Microscopy & Kerman & [33] \\
\hline Sheep & 250 & 101 & T. lestoquardi and T. ovis & Nested PCR & $\begin{array}{l}\text { Western half of } \\
\text { Iran (Sari, Rasht, } \\
\text { Urmia, Ilam, and } \\
\text { Ahvaz) }\end{array}$ & {$[7]$} \\
\hline Cattle & 52 & 19 & T. annulata & PCR-RFLP & Azerbaijan & [34] \\
\hline Cattle & 52 & 30 & T. annulata & PCR-RFLP & $\begin{array}{l}\text { Kurdistan and } \\
\text { Kermanshah }\end{array}$ & \\
\hline Cattle & 1202 & 706 & T. annulata & PCR & $\begin{array}{l}\text { Isfahan, } \\
\text { Khuzestan, } \\
\text { Chaharmahal } \\
\text { va Bakhtiari, } \\
\text { Kohgiluyeh va } \\
\text { Boyer Ahmad and } \\
\text { Lorestan }\end{array}$ & {$[35]$} \\
\hline Cattle & 160 & 34 & T. orientalis and $T$. annulata & $\begin{array}{l}\text { Semi-nested } \\
\text { PCR }\end{array}$ & Golestan & {$[36]$} \\
\hline Sheep & 165 & 9 & T. annulata and T. ovis & PCR & Tehran & [37] \\
\hline Sheep & 568 & 73 & Theileria spp. & Microscopy & Ilam & [38] \\
\hline Sheep & 100 & 12 & Theileria spp. & Microscopy & Lorestan & [39] \\
\hline Sheep & 300 & 6 & Theileria spp. & Microscopy & Tehran & {$[40]$} \\
\hline Sheep & 100 & 46 & T. ovis and T. annulata & $\begin{array}{l}\text { Semi-nested } \\
\text { PCR }\end{array}$ & Fasrs & [41] \\
\hline Sheep & 90 & 68 & T. ovis and T. lestoquardi & $\begin{array}{l}\text { Semi-nested } \\
\text { PCR }\end{array}$ & North Khorasan & {$[42]$} \\
\hline Sheep & 452 & 295 & $\begin{array}{l}\text { T. ovis, T. lestoquardi and } \\
\text { T. annulata }\end{array}$ & $\begin{array}{l}\text { Semi-nested } \\
\text { PCR }\end{array}$ & Razavi Khorasan & {$[43]$} \\
\hline Cattle & 176 & 42 & Theileria spp. & PCR & Isfahan & {$[44]$} \\
\hline Cattle & 270 & 20 & T. annulata & PCR & $\begin{array}{l}\text { Yazd, North } \\
\text { Khorasan and } \\
\text { Mazandaran }\end{array}$ & [45] \\
\hline Horses & 165 & 47 & T. equi & PCR & Khuzestan & {$[46]$} \\
\hline
\end{tabular}


Table-1: (Continued).

\begin{tabular}{|c|c|c|c|c|c|c|}
\hline Animal & $\begin{array}{c}\text { No. of } \\
\text { examined }\end{array}$ & $\begin{array}{l}\text { No. of } \\
\text { positive }\end{array}$ & Species & $\begin{array}{l}\text { Laboratory } \\
\text { method }\end{array}$ & Place (province) & References \\
\hline Horses & 240 & 41 & T. equi & PCR & West Azerbaijan & $\begin{array}{c}\text { [47]\{Malekifard, } \\
\text { 2014 \#2067\} } \\
\text { \{Malekifard, 2014 } \\
\text { \#2067; Malekifard, } \\
\text { 2014 \#2067\} }\end{array}$ \\
\hline Horses & 100 & 53 & T. equi & IFAT & North Khorasan & {$[48]$} \\
\hline Horses & 205 & 45 & T. equi & PCR & $\begin{array}{l}\text { North Khorasan } \\
\text { and Yazd }\end{array}$ & [49] \\
\hline Sheep & 119 & 106 & Theileria spp. & PCR & Khuzestan & [50] \\
\hline Cattle & 150 & 43 & Theileria spp. & PCR & Isfahan & [51] \\
\hline Donkeys & 106 & 54 & T. equi & Multiplex-PCR & North Khorasan & [52] \\
\hline Cattle & 138 & 13 & T. annulata & PCR & Kermanshah & [53] \\
\hline Horses & 59 & 21 & T. equi & PCR & Khuzestan & [54] \\
\hline Sheep & 150 & 19 & T. lestoquardi and T. ovis & PCR & Lorestan & {$[55]$} \\
\hline Cattle & 150 & 84 & T. annulata & PCR & Kerman & {$[56]$} \\
\hline Cattle & 100 & 4 & T. annulata & PCR & Yazd & [57] \\
\hline Goats & 100 & 0 & Theileria & Microscopy & Razavi Khorasan & {$[58]$} \\
\hline Sheep & 80 & 59 & Theileria & PCR & $\begin{array}{l}\text { Sistan and } \\
\text { Baluchestan }\end{array}$ & {$[59]$} \\
\hline Cattle & 160 & 60 & T. annulata & PCR & $\begin{array}{l}\text { Sistan and } \\
\text { Baluchestan }\end{array}$ & {$[60]$} \\
\hline Cattle & 138 & 37 & Theileria & $\begin{array}{l}\text { Semi-nested } \\
\text { PCR }\end{array}$ & West Azerbaijan & {$[61]$} \\
\hline Goat & 400 & 39 & T. lestoquardi & PCR & West Azerbaijan & [62] \\
\hline Cattle & 193 & 76 & T. annulata and $T$. orientalis & Molecular & West Azerbaijan & [63] \\
\hline Buffalo & 291 & 10 & & assays & & \\
\hline Cattle & 51 & 2 & T. lestoquardi and T. annulata & PCR & Khuzestan & [64] \\
\hline Horse & 90 & 10 & T. equi & PCR & $\begin{array}{l}\text { Isfahan and } \\
\text { Shahrekord }\end{array}$ & {$[65]$} \\
\hline
\end{tabular}

NR: Not reported, T. lestoquardi=Theileria lestoquardi, T. annulata=Theileria annulata, $T$. ovis=Theileria ovis, T. orientalis=Theileria orientalis, $T$. equi=Theileria equi, PCR=Polymerase chain reaction, IFAT=Indirect fluorescent antibody test, ELISA=Enzyme-linked immunosorbent assays, RFLP=Restriction fragment length polymorphism

Table-2: The results of Egger's test to assess publication bias.

\begin{tabular}{lccc}
\hline Animals & Number of studies & bias & p \\
\hline Cattle & 25 & 1.08 & 0.21 \\
Sheep & 24 & 1.37 & 0.56 \\
Horses & 7 & 2.30 & 0.11 \\
Overall & 56 & 1.67 & 0.13 \\
\hline
\end{tabular}

on the economy. The disease is widespread and well known in several parts of Iran, which affects animals' husbandry and their productions in the country. The majority cases of theileriosis occurred in June-July and the lowest in March-April in northwestern and southeastern Iran $[4,66]$. In addition, the high prevalence of ovine theileriosis in different areas of Iran is probably identified with a few issues, for example, vector seasonal frequency, weather and environmental alterations, host susceptibility, ticks resistance to insecticide, high frequency of tick-infested in sheep versus cattle, and insufficient preventive policies. [4,67-70].

Several hard tick genera including Amblyomma, Haemaphysalis, Hyalomma, and Rhipicephalus as main vectors of theileriosis are scattered in all ruminant grazing lands, and accordingly, the chance of transmission of it is increased [48].

In our study, the pooled prevalence of livestock theileriosis is approximated to be $19 \%$ in Iran.
Moreover, the prevalence rate of theileriosis in various geographical regions demonstrated that there were assorted zones in Iran with high prevalence rates in cattle with $58 \%$ in Razavi Khorasan, northeastern, and $57.6 \%$ in Kermanshah, western Iran, in sheep with $71 \%$ in Sistan and Baluchestan, Eastern, $70 \%, 55.6 \%$ in North Khorasan and Razavi Khorasan, respectively; in horses with $53 \%$ in North Khorasan provinces. Furthermore, the average prevalence of infection rate was notably lower in the central and northern provinces of the country.

Our findings are in symmetry with a study carried out on sheep and goats in Pakistan, Eastern neighborhood of Iran, in 2012, by microscopic examination, $11.2 \%$ samples were positive for Theileria spp. The prevalence of Theileria spp. was $13.9 \%$ and $8.2 \%$ in sheep and goat, respectively [71].

In Turkey, as western neighborhood of Iran, the prevalence of $T$. buffeli/T. orientalis was reported between $0.9 \%$ and $13.6 \%$ using PCR, and T. annulata was reported between $0 \%$ and $60.5 \%$ using microscopic method. The seroprevalence of T. annulata was found between $1.8 \%$ and $91.4 \%$ by IFAT. The prevalence of $T$. annulata by molecular techniques was between $15.4 \%$ and $61.2 \%$. The prevalence of $T$. recondita/T. ovis by microscopic examination of thin blood smears was varied from $0 \%$ to $41.3 \%$ and its seroprevalence was 


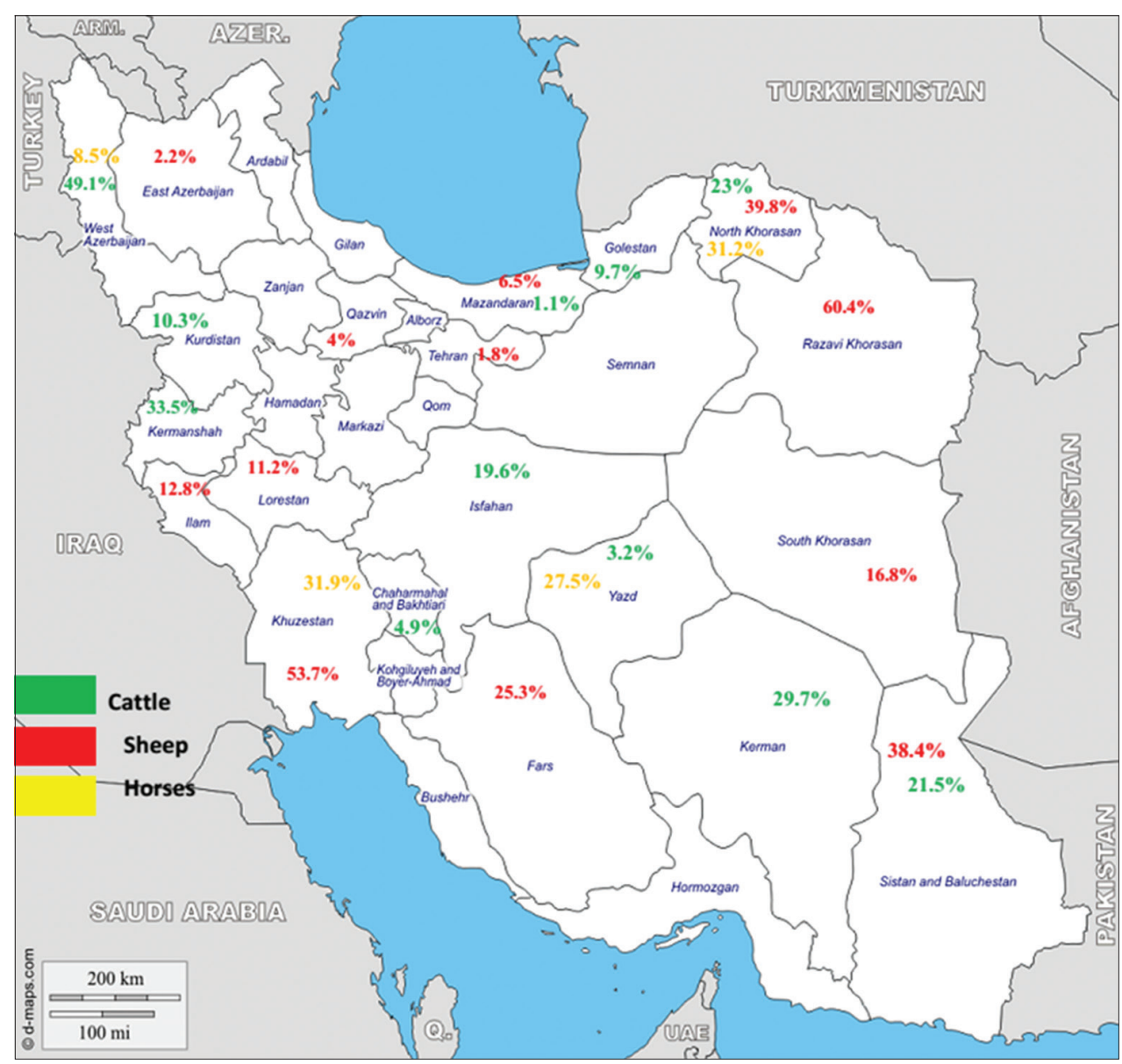

Figure-2: Detailed presentation of overall distribution of Theileria spp. infection in the provinces of Iran.

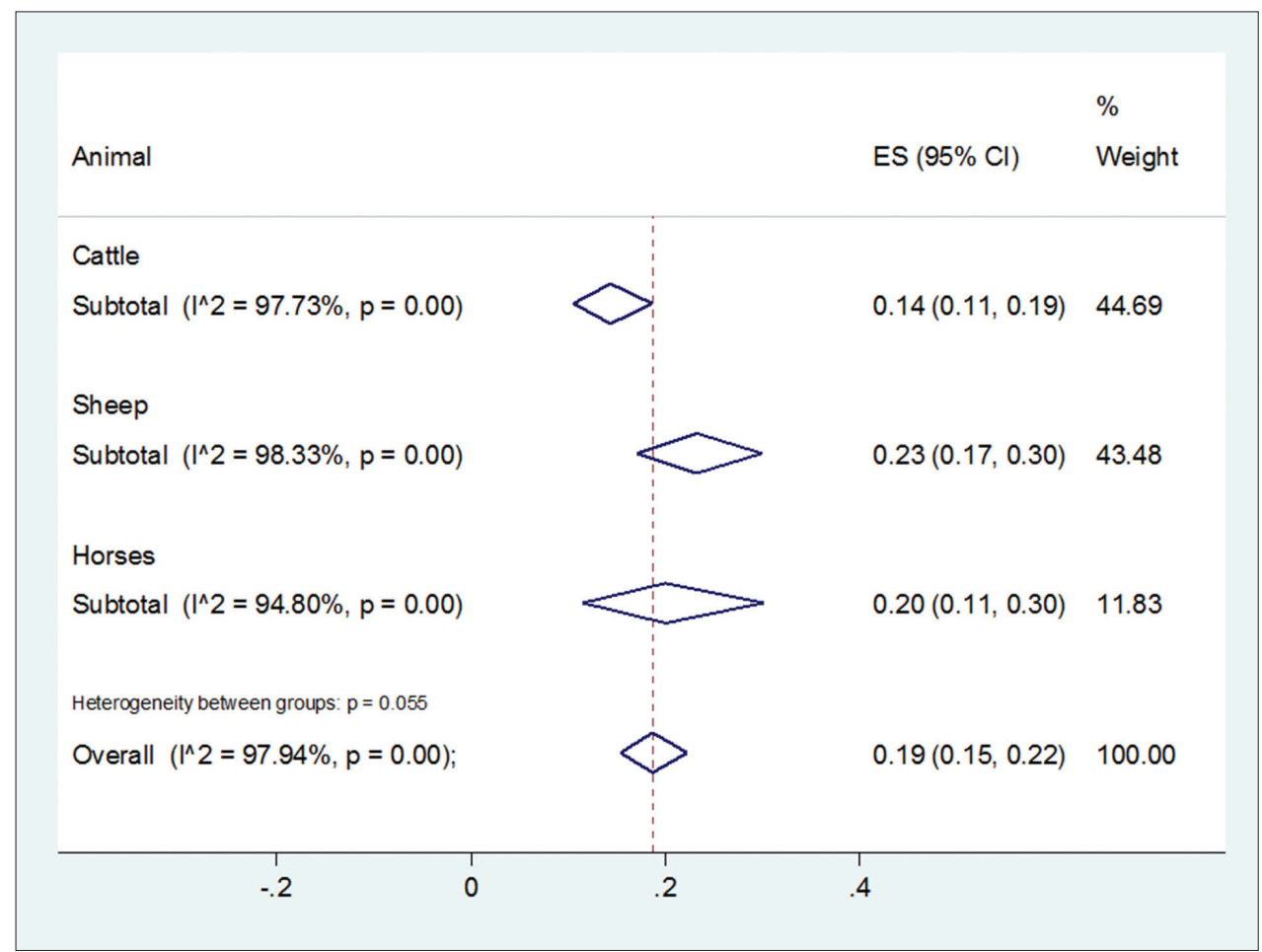

Figure-3: Estimate of the prevalence of Theileria infection among herbivores based on 56 studies in different years and areas in Iran. The pooled random effect size and 95\% confidence interval represents by diamond, 19\% (15-22\%). Overall heterogeneity based on random effect model was showed by $\mathrm{I}^{2}(97.94 \%, \mathrm{p}<0.001)$. The vertical dash line represents overall estimate, and the vertical solid line represents the value of null hypothesis. 
found to be between $8.2 \%$ and $63.2 \%$ by IFAT. Weather conditions, the tick seasonal activities, and ecological conditions of Turkey and Kurdistan region of Iraq are extremely close to western and northwestern Iranian provinces, e.g., West and East Azerbaijan [32,72-75].

On the whole, our study showed that the average prevalence rate of ovine, bovine, and equine theileriosis was 23,14 , and $20 \%$, respectively. In this study, five species of Theileria were identified which abundantly found in different livestock, would be considered as causal agents of theileriosis in the country. Our data showed that ovine theileriosis caused by T. lestoquardi infection is common in southern, southwestern, and southeastern parts of Iran and T. ovis is prevalent all over the country; even though the latest species is the main species in northern, western, and northwestern areas of Iran [7,24,43].

Regarding bovine theileriosis in Iran, our data are similar to the prior epidemiological surveys of T. orientalis and T. annulata in neighboring countries. For example, in four districts of Punjab, Pakistan, the pooled prevalence of $T$. orientalis was approximately $24.5,6$, and $6.1 \%$ by multiplexed tandem PCR method in the imported and native Pakistani cattle and buffaloes, respectively [76].

Equine theileriosis is caused due to T. equi and Babesia caballi and it is widespread in the most of tropical parts of countries in Europe, Africa, Asia, and countries surrounding Iran such as Turkey [77,78], Oman [79], Saudi Arabia [80], Kuwait [81], United Arab Emirates [82], and Iraq [83] as well as from other countries, found varying degrees of parasite prevalence. Overall, T. equi is most common and malignant than $T$. caballi in many endemic parts of the world including Iran [49].

In a study from Iran, with PCR assay showed infection with T. equi in $50.9 \%$ of the donkeys [52]. The frequency of $T$. equi infections was recorded from $31.8 \%$ of donkeys in Brazil using PCR method [84], $0.5-12 \%$ of blood smears of donkeys in Ethiopia [85-89]. Seropositivity rates of T. equi infection were in $73.8 \%$ of donkeys in Brazil [84], $55.7 \%$ in Ethiopia [87], 9.6\% in China [88], 47.2\% in Spain [89], and $4-13 \%$ in Turkey $[90,91]$.

Our findings and recent data show that $T$. equi and T. caballi were common in horse populations in provinces of Iran including East and West Azerbaijan, North Khorasan, and Khuzestan $[23,47]$.

Herbivores theileriosis is answerable for high mortality and morbidity of livestock and subsequently fizzling economy, stunning effects on traditional and industrial animal breeding, in addition falling control approaches $[4,92]$.

The diagnosis of theileriosis is based on traditional methods including microscopic examination (mostly thick and thin Giemsa-stained blood smears), and clinical symptoms. On the other hand, since the microscopic method has low sensitivity, this technique is not being reliable for the detection of asymptomatic and or subclinical infections because of the low parasitemia and or low virulence [6,93]. Moreover, serological assays such as ELISA and IFAT have also many disadvantages such as cross-reactivity between various species. Recently, molecular tools have picked up notoriety and prominence for detection and characterization proof of various pathogens. Altogether, serological and molecular tools may be appropriate in mild and also asymptomatic and or subclinical infections [6,93-95].

Given that there is a large number of studies about distribution status of ruminant theileriosis contrasting babesiosis [62] and a limited number of studies regarding equine theileriosis in Iran. Moreover, the most of studies are concentrated on ovine theileriosis, so an urgent need for updated data about the prevalence of theileriosis in Iranian equine theileriosis would be required. Nonetheless, a few unpublished data concerning ovine and bovine theileriosis are available in local provincial veterinary health and management centers gathered from private veterinary clinics and diagnostic laboratories in the various parts of Iran, which even though they are not exactly noteworthy and valid for appraisal.

\section{Conclusion}

The high occurrence of Theileria infection in domestic livestock in Iran, frequently among sheep, confirm the endemic and stable situations of theileriosis in the studied regions particularly northeastern and western provinces of the country and maybe a warning for animal welfare and health economy. In brief, our data offer valuable and encouraging information as regards the current situation of theileriosis in domestic herbivores in Iran, which might be useful for active and passive surveillance and preventing plans for the disease. Further investigation and monitoring will be needed to expand the surveillance and control policies, such as quite vaccination full coverage and improvement the traditional diagnostic tools and assessment the pesticide resistance in ticks to reduce the mortality and morbidity of theileriosis among livestock and consequently decrease the risk of outbreaks and economic failure and public health hazardous in Iran.

\section{Authors' Contributions}

MS, MMH, FE, and SA made searching strategy paper selection and wrote the manuscript draft, MF and HZH designed all steps of the study, SHT analyzed the extracted data. All authors read, revised, and approved the final manuscript.

\section{Acknowledgments}

The Vice Chancellor of Research and Technology, Mazandaran University of Medical Sciences, Iran provided funding for this systematic review and meta-analysis (grant number: 2980).

\section{Competing Interests}

The authors declare that they have no competing interests. 


\section{References}

1. Demessie, Y. and Derso, S. (2015) Tick borne hemoparasitic diseases of ruminants: A review. Adv. Biol. Res., 9: 210-224.

2. Gul, N., Ayaz, S., Gul, I., Adnan, M., Shams, S. and ul Akbar, N. (2015) Tropical theileriosis and east coast fever in cattle: Present, past and future perspective. Int. J. Curr. Microbiol. App. Sci, 4: 1000-1018.

3. Uilenberg, G. (1995) International collaborative research: Significance of tick-borne hemoparasitic diseases to world animal health. Vet. Parasitol., 57: 19-41.

4. Kalani, H., Fakhar, M. and Pagheh, A. (2012) An overview on present situation babesiosis and theileriosis and their distribution of ticks in Iran. Iran. J. Med. Microbiol., 5: 59-71.

5. Gubbels, M.J., Katzer, F., Hide, G., Jongejan, F. and Shiels, B.R. (2000) Generation of a mosaic pattern of diversity in the major merozoite-piroplasm surface antigen of Theileria annulata. Mol. Biochem. Parasitol., 110: 23-32.

6. Mans, B.J., Pienaar, R. and Latif, A.A. (2015) A review of Theileria diagnostics and epidemiology. Int. J. Parasitol., 4: 104-118.

7. Zaeemi, M., Haddadzadeh, H., Khazraiinia, P., Kazemi, B. and Bandehpour, M. (2011) Identification of different Theileria species (Theileria lestoquardi, Theileria ovis, and Theileria annulata) in naturally infected sheep using nested PCR-RFLP. Parasitol. Res., 108: 837-843.

8. Bishop, R., Musoke, A., Morzaria, S., Gardner, M. and Nene, V. (2004) Theileria: Intracellular protozoan parasites of wild and domestic ruminants transmitted by ixodid ticks. Parasitol., 129: 271-283.

9. Kirvar, E., Ilhan, T., Katzer, F., Wilkie, G., Hooshmand-Rad, P. and Brown, D. (1998) Detection of Theileria lestoquardi (hirci) in ticks, sheep, and goats using the polymerase chain reaction. Ann. N. Y. Acad. Sci., 849: 52-62.

10. Shayan, P. and Rahbari, S. (2005) Simultaneous differentiation between Theileria spp. and Babesia spp. on stained blood smear using PCR. Parasitol. Res., 97: 281-286.

11. Altay, K., Dumanli, N., Holman, P.J. and Aktas, M. (2005) Detection of Theileria ovis in naturally infected sheep by nested PCR. Vet. Parasitol., 127: 99-104.

12. Khaki, Z., Rahbari, S. and Norouzian, I. (1999) A study of theileriosis malignant hematological and biochemical findings in sheep. J. Vet. Res., 54: 49-52.

13. Navidpour, S., Hashemi Fesharaki, R. and Goudarzi, M. (2000) The Study Of Blood Protozoa in Buffaloes In Khouzestan. Available from: http://www.agris.fao.org/ agris-search/search.do?recordID=IR2012013493. Accessed on 28-10-2017.

14. Sakha, M., Radfar, M. and Janbaz, M. (2001) evaluation of bovine theileriosis in 372 cases during spring and summer 1377, Gonabad-Iran. Iranian. J. Vet. Res., 2: 187-192.

15. Maleki, S. (2002) Case study of Theileria contamination in liver of diseased sheep perished and slaughtered in the slaughterhouse of Khorramabad. J. Vet. Res., 57: 99-101.

16. Meshgi, B., Shahgolian, L., Momtaz, H. and Samiapour, V. (2003) A prevalence of theileriosis in cattle in Shahr-e-Kord township in Iran. Pajouhesh. Sazandegi., 2: 41-43.

17. Haji, K.M.R., Lotf Elahzadeh, S. and Marzban, K. (2003) Investigation of prevalance of Theileria sp. infection and interrelationship with clinical signs at Ghaemshahr abattoir. J. Vet. Res., 58: 101-103.

18. Morshedi, A., Horr-yadollahi, M.R., Tavassoli, M. and Dalir, N.B. (2003) A seroprevalence survey of Theileria infection by ELISA, compare with blood-smear observation in cattle. J. Vet. Res, 58: 319-322.

19. Ranjbar-Bahadori, S., Lotfolahzadeh, S. and Tavasoli, A. (2004) Survey the contamination of sheep slaughtered in the municipal city of Sari blood protozoa. Anim. Sci., 64: 1-3.

20. Razmi, G.R., Eshrati, H. and Rashtibaf, M. (2006) Prevalence of Theileria spp. infection in sheep in South Khorasan province, Iran. Vet. Parasitol., 140: 239-243.

21. Mozafari, A., Nourolahi, F.S.R. and Mohamadi, V. (2007)
Frequency of Theileria in cattle in farms of Zahedan. Iranian. J. Vet. Res., 3: 67-70.

22. Akradi, L. (2007) A survey of bovine theileriosis in carcasses of Sanandaj slaughterhouse. J. Vet. Med., 2: 44-48.

23. Habibi, G., Esmaeil-Nia, K., Bozorgi, S., Najjar, E., Hashemi-Fesharki, R. and Bordbar, N. (2007) PCR-based detection of Theileria infection and molecular characterization of Tams1 T. annulata vaccine strain. Arch. Razi. Instit., 62: 83-89.

24. Hadadzadeh, H., Khazrainia, P., Heidarpour, M. and Zaeemi, M. (2010) Geographic distribution of different Theileria species in sheep in Iran. Fourth Asean Congress of Tropical Medicine and Parasitology 2010.

25. Khazrainia, P., Haddadzadeh, H., Kazemi, B., Heidarpour, M. and Aktas, M. (2008) Molecular identification of ovine Theileria species in Ferdos (South Khorasan province) East of Iran, Paper presented at the VI International Conference on Ticks and Tick Borne Pathogens.

26. Razmi, G.R., Barati, F. and Aslani, M. (2009) Prevalence of Theileria annulata in dairy cattle in Mashhad area, Iran. $J$. Vet. Parasitol., 23: 81-83.

27. Bami, M.H., Haddadzadeh, H., Kazemi, B., Khazraiinia, P., Bandehpour, M. and Aktas, M. (2009) Molecular identification of ovine Theileria species by a new PCR-RFLP method. Vet. Parasitol., 161: 171-177.

28. Heidarpour, B.M., Khazraiinia, P., Haddadzadeh, H. and Kazemi, B. (2010) Identification of Theileria species in sheep in the eastern half of Iran using nested PCR-RFLP and microscopic techniques. Iranian. J. Vet. Res., 11: 262-266.

29. Ghaemi, P., Hoghooghi, R.N., Shayan, P. and Eckert, B. (2011) Study on the protozoal infection of Theileria species in traditional animal husbandry in two ecological regions of Golestan province, Iran. Vet. Res., 1: 51-59.

30. Hashemzadeh, F.H., Shahbazi, P. and Fard, M.R.F. (2011) The infestation rate of heamoparasite in slaughtered sheep and goats of Tabriz abattoir 2009. J. Food. Hyg., 1: 17-21.

31. Hoghooghi-Rad, N., Ghaemi, P., Shayan, P., Eckert, B. and Sadr-Shirazi, N. (2011) Detection of native carrier cattle infected with Theileria annulata by semi-nested PCR and smear method in Golestan Province of Iran. World. Appl. Sci. J., 12: 317-323.

32. Tavassoli, M., Tabatabaei, M., Nejad, B., Tabatabaei, M., Najafabadi, A. and Pourseyed, S. (2011) Detection of Theileria annulata by the PCR-RFLP in ticks (Acari, Ixodidae) collected from cattle in West and North-West Iran. Acta. Parasitol., 56: 8-13.

33. Zadeh, S.S., Fathi, S., Dehaghi, M.M., Asl, E.N. and Nezhad, H.A. (2011) Survey of Theileria annulata and Anaplasma marginale in cattle in Kerman area, Southeast of Iran. Astrocytosis as a Biomarker for Late Stage Human African Trypanosomiasis in the Vervet Monkey Model., Southeast of Iran. p61.

34. Akbari, JJ.J., Tavassouli, M, Tabatabai, M. and Shafiei, R. (2012) Molecular survey of Theileria annulata in cattle by PCR-RFLP method in Iran. J. Bacteriol. Parasitol., 3: 2.

35. Dehkordi, F.S., Parsaei, P., Saberian, S., Moshkelani, S., Hajshafiei, P. and Hoseini, S. (2012) Prevalence study of Theileria annulata by comparison of four diagnositcs Bulgarian. J. Vet. Med., 15: 123-130.

36. Ghaemi, P., Hoghooghi-Rad, N., Shayan, P. and Eckert, B. (2012) Detection of Theileria orientalis in Iran by seminested PCR. Parasitol. Res., 110: 527-531.

37. Shemshad, M., Shemshad, K., Sedaghat, M.M. and Rafinejad, J. (2012) Prevalence of ovine and bovine theileriosis in domestic ruminants based on 18s rRNA gene and microscopic techniques in Qazvin Province, Iran. J. Pure. Appl. Microbiol., 6: 627-632.

38. Bahrami, A., Hosseini, E. and Razmjo, M. (2013) Theileriosis in grazing sheep and its interrelation with the reptiles ticks. Global. Vet., 10: 599-606.

39. Hoghooghi, R.N., Hashemi, S. and Abdigoudarzi, M. (2013) Detection of Theileria ovis in vector ticks by polymerase 
chain reaction method (PCR) in lorestan province. Vet. Clin. Pathol., 2: 1828-1834.

40. Tahamtan, M.H., Nabian, S., Khodaveisi, M., Ronaghi, H. and Sadeghian, A.G. (2013) Study on prevalence of blood parasites of sheep and detection of their vectors using methyl green pyronin in Varamin, Iran. Eur. J. Exp. Biol., 3: 11-15.

41. Yaghfoori, S., Razmi, G. and Heidarpour, M. (2013) Molecular detection of Theileria spp. in sheep and vector ticks in Fasa and Kazeroun areas, Fars province, Iran. Arch. Razi. Instit., 68: 159-164.

42. Rashidi, A. and Razmi, G. (2012) Molecular detection of Theileria spp. in sheep and vector ticks in the North Khorasan Province, Iran. Trop. Anim. Health Prod., 45: 299-303.

43. Razmi, G., Pourhosseini, M., Yaghfouri, S., Rashidi, A. and Seidabadi, M. (2013) Molecular detection of Theileria spp. and Babesia spp. in sheep and ixodid ticks from the northeast of Iran. J. Parasitol., 99: 77-81.

44. Noaman, V. (2013) A molecular study on Theileria and Babesia in cattle from Isfahan province, Central Iran. $J$. Parasit. Dis., 37: 208-210.

45. Cheshti, B., Razmi, G. and NaghibI, A. (2013) A comparative study on haemoprotozoa infection in apparently healthy cattle in different geographical areas of Iran using PCR method. J. Vet. Microbiol., 9: 139-145.

46. Bahrami, S., Ghadrdan, A., Pourmahdi, B.M. and Vafayi, S.M. (2014) Epidemiology of Theileria equi in Persian Arab horses from Iran. Vet. Med., 59: 409-414.

47. Malekifard, F., Tavassoli, M., Yakhchali, M. and Darvishzadeh, R. (2014) Detection of Theileria equi and Babesia caballi using microscopic and molecular methods in horses in suburb of Urmia, Iran. Vet. Res. Forum., 5: 129-133.

48. Abedi, V., Razmi, G., Seifi, H. and Naghibi, A. (2014) Molecular and serological detection of Theileria equi and Babesia caballi infection in horses and ixodid ticks in Iran. Tick. Tick. Born. Dis., 5: 239-244.

49. Bahrami, S., Ghadrdan, A., Mirabdollahi, S. and Fayed, M. (2014) Diagnosis of subclinical equine theileriosis in center of Iran using parasitological and molecular methods. Trop. Biomed., 31: 110-117.

50. Jalali, S.M., Khaki, Z., Kazemi, B., Rahbari, S., Shayan, P., Bandehpour, M. and Yasini, S.P. (2014) Molecular detection and identification of Theileria species by PCR-RFLP method in sheep from Ahvaz, Southern Iran. Iran. J. Parasitol., 9: 99.

51. Noaman, V. (2014) Comparison of molecular and microscopic technique for detection of Theileria spp. in carrier cattle. J. Parasit. Dis., 38: 64-67.

52. Abedi, V., Razmi, G., Seifi, H. and Naghibi, A. (2015) Molecular detection of equine piroplasms in donkeys (Equus asinus) in North Khorasan province, Iran. Iran. J. Vet. Res., 16: 202.

53. Ghashgai, O., Yakhchali, M. and Sohrabi, S. (2015) PCRRELP for detecting of Theileria annulata infection in cattle and Hyalomma species in Kermanshah Province, Iran. Arch. Razi. Institut., 70: 7-12.

54. Jalali, M., Raki, A., Shahriari, A., Ghadrdan, M.A., Hamidi, N.H. and Jelodar, M. (2015) study of hematology and clinical signs piroplasmosis in Arab thoroughbreds in Ahwaz Iran. J. Vet. Res., 11: 65-75.

55. Hashemi, S. and Kh, E. (2015) Molecular identification of Theileria ovis and T. lestoquardi in vector ticks of Ixodidae family in Lorestan province. Iranian. Vet. J., 3: 97-104.

56. Nourollahi-Fard, S.R., Khalili, M. and Ghalekhani, N. (2015) Detection of Theileria annulata in blood samples of native cattle by PCR and smear method in Southeast of Iran. J. Parasit. Dis., 39: 249-252.

57. Khodabandeh, S. and Razmi, G. (2015) Molecular detection of Theileria species and its vectors in cattle in Yazd area by Semi-nested PCR method. J. Vet. Res., 70: 249-253.
58. Azghandi, M. and Razmi, G. (2015) Identification of Babesia and Theileria species in goats and ticks with smear observation and molecular examination in Mashhad, Khorasan Razavi province, Iran. J. Vet. Res., 70: Pe1-Pe5.

59. Sharifi, N., Ganjali, M., Nabavi, R. and Saadati, D. (2016) A study on prevalence and identification of ovine Theileria and Babesia infection in Zabol using PCR method. $J$. Parasit. Dis., 40: 1535-1539.

60. Majidiani, H., Nabavi, R., Ganjali, M. and Saadati, D. (2016) Detection of Theileria annulata carriers in HolsteinFriesian (Bos taurus taurus) and Sistani (Bos taurus indicus) cattle breeds by polymerase chain reaction in Sistan region, Iran. J. Parasit. Dis., 40: 1184-1188.

61. Yamchi, J.A. and Tavassoli, M. (2016) Survey on infection rate, vectors and molecular identification of Theileria annulata in cattle from North West, Iran. J. Parasit. Dis., 40: 1071-1076.

62. Mohammadi, S.M., Esmaeilnejad, B. and Jalilzadeh-Amin, G. (2017) Molecular detection, infection rate and vectors of Theileria lestoquardi in goats from West Azerbaijan province, Iran. Vet. Res. Forum., 8: 139-144.

63. Narimani, B., Rad, N.H., Shayan, P. and Rahbari, S. (2017) Molecular and microscopic detection of Theileria spp. among cattle and buffaloes in West Azarbaijan, Iran. Arch. Razi. Inst., 72: 189-195.

64. Jalali, S.M., Jolodar, A., Rasooli, A. and Darabifard, A. (2016) Detection of Theileria lestoquardi cross infection in cattle with clinical theileriosis in Iran. Acta Parasitol., 61: 756-761.

65. Taktaz-hafshejani, T. and Khamesipour, F. (2017) Molecular detection of Theileria equi and Babesia caballi infections in horses by PCR method in Iran. Kafkas. Univ. Vet. Fak. Derg., 23: 161-164.

66. Haghi, S.M.M., Fakhar, M., Sharif, M. and Keighobadi, M. (2014) An overview on different diagnostic methods for babesiosis. J. Mazandaran. Univ. Med. Sci., 23: 283-295.

67. Pipano, E. (1991) Observations on the seasonal distribution of blood parasites in sheep in Israel. Israel. J. Vet. Med., 46: 37-38.

68. Yeruham, I., Handani, A., Galker, F., Rosen, S. and Schlien, J. (1992) A field study of haemoparasites in two flocks of sheep in Israel. Israel. J. Vet. Med., 47: 107-111.

69. Nabian, S. and Rahbari, S. (2008) Occurrence of soft and hard ticks on ruminants in Zagros mountainous areas of Iran. J. Arthr. Dis., 2: 16-20.

70. Rahbari, S., Nabian, S. and Shayan, P. (2007) Primary report on distribution of tick fauna in Iran. Parasitol. Res., 101: 175-177.

71. Naz, S., Maqbool, A., Ahmed, S., Ashraf, K., Ahmed, N. and Saeed, K. (2012) Prevalence of theileriosis in small ruminants in Lahore-Pakistan. J. Vet. Anim. Sci., 2: 16-20.

72. Vatansever, Z., İça, A., Deniz, A., Nalbantoğlu, S., Karaer, Z. and Çakmak, A. (2003) Ankara yöresinde sığırlarda kene kaynaklı protozoon enfeksiyonlarının yayılışının reverse lineblotting (RLB) ve indirek floresan antikor testi (IFAT) ile saptanmas. Ulusal. Parazitol. Kong., 194: 1465-1469.

73. Ica, A., Inci, A. and Yildirim, A. (2007) Parasitological and molecular prevalence of bovine Theileria and Babesia species in the vicinity of Kayseri. Turk. J. Vet. Anim. Sci., 31: 33-38.

74. Çiçek, H., Cicek, H., Eser, M. and Tandogan, M. (2009) Current status of ruminant theileriosis and its economical impact in Turkey. Türk. Parazitol. Derg., 33: 273-279.

75. Al-Saeed, A.T.M., Omer, L.T., Abdo, J., Habibi, G., Salih, D.A. and Seitzer, U. (2010) Epidemiological studies on tropical theileriosis (Theileria annulata infection of cattle) in Kurdistan Region, Iraq. Parasitol. Res., 106: 403.

76. Gebrekidan, H., Abbas, T., Wajid, M., Ali, A., Gasser, R.B. and Jabbar, A. (2017) Molecular characterisation of Theileria orientalis in imported and native bovines from Pakistan. Infect. Genet. Evol., 47: 19-25.

77. Sevinc, F., Maden, M., Kumas, C., Sevinc, M. and 
Ekici, O.D. (2008) A comparative study on the prevalence of Theileria equi and Babesia caballi infections in horse sub-populations in Turkey. Vet. Parasitol., 156: 173-177.

78. Karatepe, B., Karatepe, M., Çakmak, A., Karaer, Z. and Ergün, G. (2009) Investigation of seroprevalence of Theileria equi and Babesia caballi in horses in Nigde province, Turkey. Trop. Anim. Health. Prod., 41: 109-113.

79. Donelli, J., Joyner, L., Graham-Jones, O. and Ellis, C. (1980) A comparison of the complement fixation and immunofluorescence antibody tests in a survey of the prevalence of Babesia equi and Babesia caballi in horses in the Sultanate of Oman. Trop. Anim. Hlt. Prod., 12: 50-60.

80. Alanazi, A.D., Alyousif, M.S. and Hassieb, M.M. (2012) Seroprevalence study on Theileria equi and Babesia caballi antibodies in horses from central province of Saudi Arabia. J. Parasitol., 98: 1015-1017.

81. Donnelly, J., Joyner, L.P. and Frank, C. (1980) Quantitative epidemiological studies on the prevalence of babesiosis in horses in Kuwait. Trop. Anim. Health. Prod., 12: 253-258.

82. Jaffer, O., Abdishakur, F., Hakimuddin, F., Riya, A., Wernery, U. and Schuster, R.K. (2010) A comparative study of serological tests and PCR for the diagnosis of equine piroplasmosis. Parasitol. Res., 106: 709-713.

83. Alsaad, K.M. (2014) Evaluation of hemogram, acute phase response, acid-base balance and blood gas analysis in newborn foals infected with babesiosis. J. Anim. Plant. Sci., 24: 738-742.

84. Machado, R.Z., Toledo, C.Z.P., Teixeira, M.C.A., André, M.R., Freschi, C.R. and Sampaio, P.H. (2012) Molecular and serological detection of Theileria equi and Babesia caballi in donkeys (Equus asinus) in Brazil. Vet. Parasitol., 186: 461-465.

85. Mekibib, B., Manegerew, M., Tadesse, A., Abuna, F., Megersa, B., Regassa, A., Mekuria, S. and Abebe, R. (2010) Prevalence of haemoparasites and associated risk factors in working donkeys in Adigudem and Kwiha districts of Tigray region, Northern Ethiopia. J. Anim. Vet. Adv., 9: 2249-2255.

86. Tefera, M., Worku, A., Tolosa, T. and Bitew, M. (2011) Prevalence and risk factors for donkey babesiosis in and around Debre Zeit, Central Ethiopia. Vet. Res., 4: 56-60.

87. Gizachew, A., Schuster, R.K., Joseph, S., Wernery, R., Georgy, N.A. and Elizabeth, S.K. (2013) Piroplasmosis in Donkeys-A Hematological and Serological Study in Central Ethiopia. J. Equine Vet. Sci., 33: 18-21.

88. Chahan, B., Zhang, S., Seo, J.Y., Nakamura, C., Zhang, G., Bannai, H., Jian, Z., Inokuma, H., Tuchiya, K., Sato, Y., Kabeya, H., Maruyama, S., Mikami, T. and Xuan, X. (2006) Seroepidemiological evidence for the possible presence of Babesia (Theileria) equi and Babesia caballi infections in donkeys in western Xinjiang, China. J. Vet. Med. Sci., 68: 753-755.

89. García-Bocanegra, I., Arenas-Montes, A., Hernández, E., Adaszek, Ł., Carbonero, A., Almería, S., Jaen-Tellez, J.A., Gutierrez-Palomino, P. and Arenas, A. (2013) Seroprevalence and risk factors associated with Babesia caballi and Theileria equi infection in equids. Vet. J., 195: 172-178.

90. Acici, M., Umur, S., Guvenc, T., Arslan, H.H. and Kurt, M. (2008) Seroprevalence of equine babesiosis in the black sea region of Turkey. Parasitol. Int., 57: 198-200.

91. Balkaya, I., Utuk, A.E. and Piskin, F.C. (2010) Prevalance of Theileria equi and Babesia caballi in donkeys from Eastern Turkey in winter season. Pak. Vet. J., 30: 245-246.

92. Ahmed, J., Yin, H., Schnittger, L. and Jongejan, F. (2002) Ticks and tick-borne diseases in Asia with special emphasis on China. Parasitol. Res., 88: 51-55.

93. Nayel, M., El-Dakhly, K.M., Aboulaila, M., Elsify, A., Hassan, H., Ibrahim, E., Salama, A. and Yanai, T. (2012) The use of different diagnostic tools for Babesia and Theileria parasites in cattle in Menofia, Egypt. Parasitol. Res., 111: 1019-1024.

94. d'Oliveira, C., Van der Weide, M., Jacquiet, P. and Jongejan, F. (1997) Detection of Theileria annulata by the PCR in ticks (Acari: Ixodidae) collected from cattle in Mauritania. Exp. Appl. Acarol., 21: 279-291.

95. Sparagano, O. (1999) Molecular diagnosis of Theileria and Babesia species. J. Vet. Parasitol., 13: 83-92.

$* * * * * * * *$ 